Research Paper

\title{
Physical and functional measures predicting long-term mortality in community-dwelling older adults: a comparative evaluation in the Singapore Longitudinal Ageing Study
}

\author{
Chin Yee Cheong ${ }^{1}$, Philip Yap ${ }^{1}$, Xinyi Gwee², Denise Q.L. Chua ${ }^{2}$, Shiou Liang Wee ${ }^{3}$, Keng Bee Yap ${ }^{4}$, \\ Tze Pin $\mathbf{N g}^{2}$ \\ ${ }^{1}$ Department of Geriatric Medicine, Khoo Teck Puat Hospital, Singapore \\ ${ }^{2}$ Gerontology Research Programme, Department of Psychological Medicine, Yong Loo Lin School of Medicine, \\ National University of Singapore, Singapore \\ ${ }^{3}$ Health and Social Sciences Cluster, Singapore Institute of Technology, Singapore \\ ${ }^{4}$ Department of Geriatric Medicine, Ng Teng Fong Hospital, Singapore
}

Correspondence to: Tze Pin Ng; email: pcmngtp@nus.edu.sg

Keywords: functional measures, gait speed, gait measurement, mortality, community-dwelling

Received: August 20, $2021 \quad$ Accepted: November 24, $2021 \quad$ Published: December 11, 2021

Copyright: (C) 2021 Cheong et al. This is an open access article distributed under the terms of the Creative Commons Attribution License (CC BY 3.0), which permits unrestricted use, distribution, and reproduction in any medium, provided the original author and source are credited.

\section{ABSTRACT}

Measures of functional status are known to predict mortality more strongly than traditional disease risk markers in old adult populations. Few studies have compared the predictive accuracy of physical and functional measures for long-term mortality. In this prospective cohort study, community-dwelling older adults $(N=2906)$ aged $55+$ (mean age $66.6 \pm 7.7$ years) were followed up for mortality outcome up to 9 years (mean 5.8 years). Baseline assessments included Timed Up-and-Go (TUG), gait velocity (GV), knee extension strength, Performance Oriented Mobility Assessment, forced expiratory volume in 1 second, Mini-Mental State Examination (MMSE), Geriatric Depression Scale, frailty, and medical morbidity. A total of 111 (3.8\%) participants died during 16976.7 person-years of follow up. TUG was significantly associated with mortality risk ( $\mathrm{HR}=2.60,95 \% \mathrm{Cl}=2.05-3.29$ per SD increase; $\mathrm{HR}=5.05,95 \% \mathrm{Cl}=3.27-7.80$, for TUG score $\geq 9 \mathrm{~s})$. In multivariate analysis, TUG remained significantly associated with mortality (HR $=1.64,95 \% \mathrm{Cl}=1.20-2.19$ per SD increase; $H R=2.66,95 \% \mathrm{Cl}=1.67-4.23$ for TUG score $\geq 9 \mathrm{~s}$ ). In multivariable analyses, GV, MMSE, Frailty Index (FI) and physical frailty, diabetes and multi-morbidity were also significantly associated with mortality. However, TUG (AUC $=0.737$ ) demonstrated significantly higher discriminatory accuracy than GV $(A U C=0.666, p$ $<0.001)$, MMSE (AUC = 0.63, $p<0.001)$, FI $(A U C=0.62, p<0.001)$, physical frailty (AUC $=0.610, p<0.001)$, diabetes (AUC $=0.582, p<0.001$ ) and multi-morbidity (AUC $=0.589, p<0.001$ ).

TUG's predictive accuracy shows surpassing predictive accuracy for long-term mortality in community-dwelling older adults.

\section{INTRODUCTION}

Previous studies have shown that traditional clinical risk factors known to be associated with mortality risk, such as smoking, obesity, chronic diseases and comorbidity in the general adult population, lose their importance in old populations, typically older than 65 years. Instead, disability, poor physical and cognitive functions were more strongly predictive of mortality $[1,2]$. This may be explained by the survival effect among individuals who remain alive while their contemporaries have already died in middle-age or younger-old age from 
smoking-, alcohol- and obesity-related diseases. Indeed, among very old people (over $75 \mathrm{~s}$ ), paradoxical inverse mortality risks are sometimes found in association with obesity and cholesterol. Smokers, drinkers and obese individuals who survive into older age may perhaps have genetic and/or environmental characteristics that protect them against the toxic effects of harmful habits. Risk factors measured at old age may not reflect lifetime exposures since non-smoker and non-drinkers may have stopped their habits for health-related reasons, and there may have been significant weight changes previously.

Clinical measures of health and functional statuses such as cognition [3], depression [4], impaired pulmonary function [5], slow gait velocity [6] and frailty [7] have been investigated and consistently shown to predict mortality among older adults. These measures are not only related to specific chronic disease(s) or multimorbidity, but also reflect the broad underlying intrinsic capacity of older people resulting from the interaction of physical and mental health declines. Few studies have evaluated various physical and functional measures together and compared their performance in predicting long-term mortality.

The Timed Up-and-Go test (TUG) is a widely used physical performance test of functional mobility in older persons, as it is easily performed without special equipment. It has high interrater and test-retest reliability [8]. TUG assesses static balance, dynamic balance, lower limbs strength $[9,10]$, and gait speed. Poor TUG performance has been linked to recurrent falls [11], impaired physical and cognitive function [12], poor quality of life [13], dementia [14] and frailty $[15,16]$. Previous studies have shown that TUG predicts all-cause mortality of older adults [17-23].

In this study, we evaluated the predictive accuracy of TUG for long-term mortality and compared its performance with those of other commonly used measures of physical strength, balance and gait, functional mobility, global cognition and depression in a cohort of over-55-year-olds participating in the Singapore Longitudinal Aging Study 2 (SLAS-2) followed up for mortality risks up to 9 years (mean of 5.8 years). We hypothesized that the TUG has surpassing accuracy for predicting long-term mortality over gait velocity (measured on the fast gait test), knee extension strength (KES), the Performance-Oriented Mobility Assessment (POMA), the Mini-Mental State Examination (MMSE), depressive symptoms (measured by the Geriatric Depression Scale), forced expiratory volume - one second $\left(\mathrm{FEV}_{1}\right)$, as well as frailty (Frailty Index and Physical Frailty phenotype) and multi- morbidity, which are two other clinical diagnoses known to predict mortality.

\section{RESULTS}

The participants have a mean age of $66.6 \pm 7.7$ years. More than half of the participants were female $(n=$ $1829,62.9 \%)$, never smokers $(n=2276,78.3 \%)$ and had hypertension $(n=1807,62.2 \%)$. (Table 1) TUG was significantly correlated $(p<0.001)$ with GV $(\mathrm{r}=$ $-0.593)$, KES $(r=-0.238)$, POMA $(\mathrm{r}=-0.430)$ and MMSE $(r=-0.326)$, as well as FEV1\% ( $\mathrm{r}=-0.133)$, GDS $(r=0.196)$, FI $(r=0.443)$, and physical frailty $(r=$ 0.356). Up to 31 Dec 2016, a total of 111 (3.8\%) participants died during a total follow up period of 16976.7 person-years. The principal causes of death were cancer $(40 \%$, including $12 \%$ lung cancer, $5 \%$ colorectal cancer), cardiovascular diseases $(25 \%$, including $10 \%$ stroke), pneumonia (15\%), COPD (5\%), kidney failure $(2 \%)$.

We found that TUG was associated with significant mortality risk, whether it was analysed as a continuous variable or a binary categorical variable. The association of TUG and mortality in an unadjusted model has the HR of 2.6 (95\% CI, 2.05$3.29, p<0.001)$ per SD increase of TUG, and HR of 5.05 (95\% CI, 3.27-7.80, $p<0.001)$ when analyzed as a binary variable $(\geq 9 \mathrm{~s}$ vs. $<9 \mathrm{~s})$. It remained significantly associated with mortality even after adjusting for baseline sociodemographic, lifestyle risk factors, as well as comorbidities (HR $=1.64,95 \% \mathrm{CI}$, $1.20-2.19, p<0.001$, per SD increase; $\mathrm{HR}=2.66$, $95 \%$ CI, 1.67-4.23, $p<0.001, \mathrm{TUG} \geq 9$ s vs. $<9$ s). (Table 2A, 2B) When all physical and functional performance measure was analyzed simultaneously in the same model with all covariates, TUG remained significantly associated with mortality $(\mathrm{HR}=1.45$, 95\% CI, 1.01-2.07, $p<0.05$, per SD increase; HR = $2.02,95 \% \mathrm{CI}, 1.26-3.25, p=0.004$ with TUG binary score). In contrast, other physical and functional performance measures were no longer significantly associated with mortality per SD score increase, except for low KES $(\mathrm{HR}=1.80,95 \% \mathrm{CI}, 1.20-2.69, p$ $=0.004)($ Table 3$)$.

TUG (AUC $=0.737$ ) demonstrated a significantly higher predictive accuracy for mortality than GV (AUC $=0.666, p<0.001)$, MMSE $(\mathrm{AUC}=0.63, p<0.001)$, FI (AUC $=0.620, p<0.001)$ and physical frailty (AUC $=0.610, p<0.001$ ). (Table 4 and Figure 1) AUCs for chronic diseases and multi-morbidity were between 0.552 and 0.589 , smoking was 0.662 , BMI and central obesity were 0.386 and 0.480 . The AUC for age was 0.730 (95\% CI, 0.681-0.778). 
Table 1. Characteristics of study participants in the Singapore Longitudinal Ageing Study (SLAS-2) cohort ( $N=2906)$.

\begin{tabular}{|c|c|c|c|c|}
\hline Characteristics & & Mean or \% & \pm SD or $(N)$ & Skewness \\
\hline Age & Mean \pm SD & 66.6 & \pm 7.7 & \\
\hline Sex & Female & 62.9 & $(1829)$ & \\
\hline \multirow[t]{2}{*}{ Ethnicity } & Chinese & 87.7 & $(2549)$ & \\
\hline & Non-Chinese (Malay, Indian and Others) & 12.3 & $(357)$ & \\
\hline \multirow[t]{3}{*}{ Education } & None & 19.4 & $(563)$ & \\
\hline & $1-6$ years & 43.2 & $(1254)$ & \\
\hline & $>6$ years & 37.5 & (1089) & \\
\hline \multirow[t]{3}{*}{ Housing type } & Low-end $1-2$ rooms & 21.3 & $(619)$ & \\
\hline & 3 rooms & 28.5 & $(827)$ & \\
\hline & $\geq 4$ rooms and others & 50.2 & $(1460)$ & \\
\hline Live alone & & 14.6 & $(424)$ & \\
\hline \multirow[t]{3}{*}{ Smoking } & Never & 78.3 & $(2276)$ & \\
\hline & Ex-smoker & 11.8 & $(344)$ & \\
\hline & Current smoker & 9.8 & (286) & \\
\hline BMI, $\mathrm{kg} / \mathrm{m}^{2}$ & Mean \pm SD & 24.2 & \pm 4.1 & \\
\hline$<18.5$ & Underweight & 5.5 & (159) & \\
\hline $18.5-29.9$ & Non-obese & 84.4 & $(2453)$ & \\
\hline$\geq 30$ & Obese & 7.5 & $(219)$ & \\
\hline Waist circumference, $\mathrm{cm}$ (men) & Mean \pm SD & 88.6 & \pm 9.9 & \\
\hline (women) & Mean \pm SD & 83.2 & \pm 10.5 & \\
\hline Central obesity (men) & Yes vs. no & 43.5 & $(469)$ & \\
\hline (women) & Yes vs. no & 61.6 & $(1127)$ & \\
\hline Physical activity score & $1-12$ & 6.2 & \pm 1.5 & \\
\hline Social activity score & $6-24$ & 11.1 & \pm 2.6 & \\
\hline Productive activity score & $4-16$ & 9.9 & \pm 1.9 & \\
\hline Multi-morbidity & $\geq 5$ vs. $0-4$ & 18.1 & $(525)$ & \\
\hline Heart disease & Yes vs. no & 8.8 & $(257)$ & \\
\hline Stroke & Yes vs. no & 3.5 & $(102)$ & \\
\hline Diabetes & Yes vs. no & 20.2 & $(587)$ & \\
\hline Hypertension & Yes vs. no & 62.2 & (1807) & \\
\hline Chronic kidney disease & Yes vs. no & 8.4 & $(244)$ & \\
\hline TUG & Mean \pm SD & 8.9 & \pm 3.7 & 4.57 \\
\hline GV (Reversed) & Mean \pm SD & 1.3 & \pm 0.35 & 0.01 \\
\hline KES (Reversed) & Mean \pm SD & 16.4 & \pm 6.7 & 1.08 \\
\hline POMA (Reversed) & Mean \pm SD & 25.6 & \pm 1.6 & -6.90 \\
\hline FEV1\% (Reversed) & Mean \pm SD & 104.4 & \pm 23.0 & -0.18 \\
\hline MMSE (Reversed) & Mean \pm SD & 27.8 & \pm 2.8 & -2.44 \\
\hline GDS & Mean \pm SD & 0.74 & \pm 1.48 & 4.38 \\
\hline Frailty Index & Mean \pm SD & 0.10 & \pm 0.06 & 1.65 \\
\hline \multirow[t]{2}{*}{ Physical frailty } & Prefrail vs. robust & 43.8 & $(1274)$ & \\
\hline & Frail vs. robust & 4.9 & $(141)$ & \\
\hline TUG & $\geq 9$ & 31.8 & (923) & \\
\hline POMA & $<25$ & 8.4 & (224) & \\
\hline GV & $>1.0 \mathrm{~m} / \mathrm{s}$ & 18.5 & (539) & \\
\hline KES & $<15 \mathrm{~kg}(\mathrm{M}),<11 \mathrm{~kg}(\mathrm{~F})$ & 30.0 & (871) & \\
\hline $\mathrm{FEV}_{1} \%$ & $<70 \%$ & 8.5 & $(248)$ & \\
\hline
\end{tabular}




\begin{tabular}{llcc} 
MMSE & $\leq 23$ & 7.6 & $(2.21)$ \\
GDS & $\geq 5$ & 2.5 & $(73)$ \\
Frailty Index & $\geq 0.15$ & 17.1 & $(498)$ \\
Physical frailty & $1-5$ & 48.7 & $(1415)$ \\
\hline
\end{tabular}

Abbreviations: TUG: Timed Up-and-Go; POMA: Performance Oriented Mobility Assessment; GV: gait velocity; KES: knee extension strength; FEV1\%: forced expiratory volume in 1 second in percentage; MMSE: Mini-Mental State Examination; GDS: Geriatric Depression Scale.

Table 2A. Hazard ratio estimates of physical and functional performance and chronic disease markers predicting mortality.

\begin{tabular}{|c|c|c|c|c|c|c|c|c|c|c|}
\hline \multirow{2}{*}{ Predictor variable } & \multirow{2}{*}{ Measurement Units } & \multicolumn{3}{|c|}{ Unadjusted } & \multicolumn{3}{|c|}{ Model 1} & \multicolumn{3}{|c|}{ Model 2} \\
\hline & & HR & $95 \% \mathrm{CI}$ & $P$ & HR & $95 \% \mathrm{CI}$ & $P$ & HR & $95 \% \mathrm{CI}$ & $P$ \\
\hline \multicolumn{11}{|l|}{ Per SD or equivalent } \\
\hline TUG & Per SD increase & 2.60 & $(2.05,3.29)$ & $* * *$ & 1.85 & $(1.42,2.42)$ & **** & 1.64 & $(1.20,2.19)$ & $* * *$ \\
\hline GV (Reversed) & Per SD increase & 1.83 & $(1.48,2.27)$ & $* * *$ & 1.47 & $(1.18,1.85)$ & $* * *$ & 1.33 & $(1.04,1.69)$ & $*$ \\
\hline KES (Reversed) & Per SD increase & 1.24 & $(1.01,1.53)$ & $*$ & 1.46 & $(1.15,1.86)$ & $* *$ & 1.38 & $(1.07,1.78)$ & * \\
\hline FEV1\% (Reversed) & Per SD increase & 1.24 & $(1.02,1.51)$ & $*$ & 1.29 & $(1.06,1.56)$ & $* *$ & 1.15 & $(0.94,1.41)$ & \\
\hline POMA (Reversed) & Per SD increase & 1.47 & $(1.09,1.97)$ & $* *$ & 1.18 & $(0.87,1.59)$ & & 1.04 & $(0.75,1.44)$ & \\
\hline MMSE (Reversed) & Per SD increase & 1.65 & $(1.31,2.08)$ & $* *$ & 1.32 & $(1.02,1.70)$ & $*$ & 1.20 & $(0.91,1.60)$ & \\
\hline GDS & Per SD increase & 1.42 & $(1.08,1.87)$ & $* *$ & 1.28 & $(0.97,1.68)$ & & 0.96 & $(0.71,1.28)$ & \\
\hline Frailty Index & Per SD increase & 1.70 & $(1.38,2.08)$ & $* * *$ & 1.41 & $(1.13,1.76)$ & $* *$ & 1.18 & $(0.90,1.53)$ & \\
\hline Physical frailty & Per point score & 1,53 & $(1.29,1.81)$ & $* * *$ & 1.27 & $(1.07,1.11)$ & $* * *$ & 1.12 & $(0.92,1.37)$ & \\
\hline Age & Per SD increase & 2.46 & $(1.97,3.06)$ & $* * *$ & 2.34 & $(1.88,2.92)$ & $* * *$ & 1.75 & $(1.34,2.28)$ & $* * *$ \\
\hline \multicolumn{11}{|l|}{ Per binary variables } \\
\hline TUG & $>=9$ vs. $<9 \mathrm{~s}$ & 5.05 & $(3.27,7.80)$ & $* * *$ & 3.28 & $(2.06,5.22)$ & $* * *$ & 2.66 & $(1.67,4.23)$ & $* * *$ \\
\hline $\mathrm{GV}$ & $<1.0 \mathrm{~m} / \mathrm{s}$ & 2.81 & $(1.91,4.12)$ & $* * *$ & 1.83 & $(1.21,2.77)$ & $* *$ & 1.69 & $(1.08,2.63)$ & * \\
\hline KES & $15 \mathrm{~kg}(\mathrm{M}), 11 \mathrm{~kg}(\mathrm{~F})$ & 2.58 & $(1.78,3.75)$ & $* * *$ & 2.06 & $(1.41,3.01)$ & $* * *$ & 2.02 & $(1.36,3.01)$ & $* * *$ \\
\hline $\mathrm{FEV}_{1} \%$ & $<70 \%$ vs. $\geq 70 \%$ & 2.10 & $(1.29,3.39)$ & $* *$ & 2.15 & $(1.32,3.53)$ & $* *$ & 1.84 & $(1.09,3.10)$ & $*$ \\
\hline POMA & $24 / 25$ & 2.20 & $(1.35,3.57)$ & $* *$ & 1.57 & $(0.96,2.58)$ & & 1.39 & $(0.82,2.38)$ & \\
\hline MMSE & $\leq 23$ vs. $\geq 24$ & 2.51 & $(1.54,4.08)$ & $* * *$ & 1.53 & $(0.90,2.57)$ & & 1.28 & $(0.73,2.23)$ & \\
\hline GDS & $\geq 5$ vs. $<5$ & 1.68 & $(1.13,2.38)$ & $* *$ & 1.66 & $(0.68,4.09)$ & & 0.76 & $(0.27,2.13)$ & \\
\hline Frailty Index & $\geq 0.15$ vs. $<0.15$ & 2.99 & $(2.03,4.39)$ & $* * *$ & 2.13 & $(1.41,3.22)$ & $* * *$ & 1.75 & $(1.08,2.82)$ & $*$ \\
\hline Physical frailty & 0 vs. $1-5$ & 2.56 & $(1.41,4.67)$ & $* *$ & 1.89 & $(1.26,2.82)$ & $* *$ & 1.58 & $(1.01,2.47)$ & $*$ \\
\hline Age & $\geq 75$ vs. $<75$ & 4.66 & $(3.21,6.78)$ & $* * *$ & 4.24 & $(2.91,6.17)$ & $* * *$ & 2.74 & $(1.75,4.31)$ & $* * *$ \\
\hline
\end{tabular}

Model 1: adjusted for age (per year) and sex. Model 2: adjusted for covariates in Model 1 (age and sex) + education, housing status, living alone, physical activity, social activity, productive activity, smoking, BMI, central obesity, heart disease, stroke, diabetes/prediabetes, hypertension, chronic kidney disease and multimorbidity.

Table 2B. Hazard ratio estimates of chronic disease and behavioural risk markers predicting mortality with base model co-variables.

\begin{tabular}{|c|c|c|c|c|c|c|c|c|c|c|}
\hline \multirow{2}{*}{\multicolumn{2}{|c|}{$\begin{array}{c}\text { Other clinical predictors and base model } \\
\text { variables }\end{array}$}} & \multicolumn{3}{|c|}{ Unadjusted } & \multicolumn{3}{|c|}{ Model 1} & \multicolumn{3}{|c|}{ Model 2} \\
\hline & & \multirow{2}{*}{$\frac{\text { HR }}{4.07}$} & \multirow{2}{*}{$\frac{\mathbf{9 5 \%} \mathbf{C I}}{(2.63,6.28)}$} & \multirow{2}{*}{$\frac{\boldsymbol{P}}{* * * *}$} & \multirow{2}{*}{$\frac{\text { HR }}{2.23}$} & \multirow{2}{*}{$\frac{\mathbf{9 5 \%} \mathbf{C I}}{(1.34,3.69)}$} & \multirow{2}{*}{$\begin{array}{l}\boldsymbol{P} \\
* *\end{array}$} & \multirow{2}{*}{$\frac{\text { HR }}{2.01}$} & \multirow{2}{*}{$\frac{\mathbf{9 5 \%} \mathbf{C I}}{(1.20,3.39)}$} & \multirow{2}{*}{$\frac{\boldsymbol{P}}{* * *}$} \\
\hline Smoking & Past (vs. Never) & & & & & & & & & \\
\hline & Current (vs. Never) & 3.59 & $(2.23,5.78)$ & $* * *$ & 2.88 & $(1.71,4.86)$ & $* * *$ & 2.53 & $(1.46,4.37)$ & ** \\
\hline \multirow[t]{2}{*}{ BMI, $\mathrm{kg} / \mathrm{m}^{2}$} & $18.5-29.9($ vs. $<18.5)$ & 0.61 & $(0.32,1.18)$ & & 0.74 & $(0.38,1.42)$ & & 0.82 & $(0.41,1.65)$ & \\
\hline & $\geq 30($ vs. $<18.5)$ & 0.30 & $(0.09,0.97)$ & $*$ & 0.49 & $(0.15,1.56)$ & & 0.52 & $(0.15,1.81)$ & \\
\hline Central obesity & Yes vs. no & 0.64 & $(0.44,0.93)$ & $*$ & 0.74 & $(0.50,1.08)$ & & 0.77 & $(0.50,1.17)$ & \\
\hline Hypertension & Yes vs. no & 2.11 & $(1.35,3.29)$ & $* *$ & 1.28 & $(0.81,2.03)$ & & 1.27 & $(0.75,2.15)$ & \\
\hline
\end{tabular}




\begin{tabular}{|c|c|c|c|c|c|c|c|c|c|c|}
\hline Diabetes & Yes vs. no & 2.16 & $(1.46,3.17)$ & $* * *$ & 1.87 & $(1.27,2.76)$ & $* *$ & 1.81 & $(1.11,2.94)$ & $*$ \\
\hline Heart disease & Yes vs. no & 2.40 & $(1.49,3.86)$ & $* * *$ & 1.66 & $(1.03,2.68)$ & $*$ & 1.48 & $(0.86,2.53)$ & \\
\hline Stroke & Yes vs. no & 2.05 & $(0.99,4.20)$ & & 1.41 & $(0.68,2.90)$ & & 1.09 & $(0.50,2.36)$ & \\
\hline Chronic kidney disease & Yes vs. no & 2.60 & $(1.63,4.15)$ & $* * *$ & 1.18 & $(0.72,1.94)$ & & 0.82 & $(0.48,1.40)$ & \\
\hline Multi-morbidity & $\geq 5$ vs. $0-4$ & 2.48 & $(1.68,3.66)$ & $* * *$ & 1.69 & $(1.12,2.52)$ & $* *$ & 1.08 & $(0.62,1.88)$ & \\
\hline Age & Single year & 1.10 & $(1.07,1.21)$ & $* * *$ & 1.09 & $(1.07,1.12)$ & $* * *$ & 1.08 & $(1.05,1.10)$ & $* * *$ \\
\hline Male sex & & 2.70 & $(1.84,3.95)$ & $* * *$ & 2.39 & $(1.63,3.51)$ & $* * *$ & 0.78 & $(0.46,1.31)$ & \\
\hline \multirow[t]{2}{*}{ Education } & $1-6$ years vs. $>6$ years & 1.32 & $(0.83,2.07)$ & & 1.07 & $(0.67,1.70)$ & & 0.96 & $(0.59,1.56)$ & \\
\hline & None vs. $>6$ years & 1.86 & $(1.13,3.06)$ & $*$ & 1.22 & $(0.70,2.12)$ & & 0.94 & $(0.52,1.70)$ & \\
\hline \multirow[t]{2}{*}{ Housing type } & 3 room vs. $4+$ room & 1.60 & $(0.96,2.66)$ & & 1.28 & $(0.77,2.14)$ & & 0.98 & $(0.57,1.67)$ & \\
\hline & $1-2$ room vs. $4+$ room & 3.49 & $(2.23,5.44)$ & $* * *$ & 2.14 & $(1.35,3.40)$ & $* * *$ & 1.64 & $(0.97,2.76)$ & \\
\hline Live alone & Yes vs. no & 1.43 & $(0.90,2.26)$ & & 1.24 & $(0.78,1.97)$ & & 0.93 & $(0.55,1.57)$ & \\
\hline Physical activity score & Per point score & 0.80 & $(0.70,0.92)$ & $* *$ & 0.83 & $(0.72,0.96)$ & $* *$ & 0.92 & $(0.79,1.09)$ & \\
\hline Social activity score & Per point score & 0.87 & $(0.80,0.95)$ & $* * *$ & 0.90 & $(0.83,0.98)$ & $*$ & 0.94 & $(0.86,1.03)$ & \\
\hline Productive activity score & Per point score & 0.72 & $(0.65,0.80)$ & $* * *$ & 0.84 & $(0.75,0.93)$ & ** & 0.92 & $(0.82,1.03)$ & \\
\hline
\end{tabular}

Abbreviation: HR: hazard ratio; ${ }^{*} p<0.05 ;{ }^{* *} p<0.01 ;{ }^{* * *} P<0.001$. Model 1 : adjusted for age (per year) and sex. Model 2 : adjusted for covariates in Model 1 (age and sex) + education, housing status, living alone, physical activity, social activity, productive activity, smoking, BMI, central obesity, heart disease, stroke, diabetes/prediabetes, hypertension, chronic kidney disease and multi-morbidity. Hazard ratios are unadjusted for functional predictors; Binary cut-offs shown are commonly used in previous research and clinical applications.

Table 3. Hazard ratios of association with mortality for physical and functional performance measures simultaneously present in the same model.

\begin{tabular}{|c|c|c|c|c|c|c|c|}
\hline \multirow{2}{*}{ Measure } & & \multicolumn{3}{|c|}{ Model 1} & \multicolumn{3}{|c|}{ Model 2} \\
\hline & & HR & $95 \% \mathrm{CI}$ & $P$ & HR & $95 \% \mathrm{CI}$ & $P$ \\
\hline \multicolumn{8}{|c|}{ Standard deviation score } \\
\hline TUG & Per SD increase & 2.17 & $(1.55,3.04)$ & $* * *$ & 1.45 & $(1.01,2.07)$ & * \\
\hline GV (Reversed) & Per SD increase & 1.10 & $(0.82,1.46)$ & & 1.02 & $(0.75,1.38)$ & \\
\hline KES & Per SD increase & 0.90 & $(0.72,1.23)$ & & 1.27 & $(0.98,1.66)$ & \\
\hline POMA & Per SD increase & 0.84 & $(0.61,1.16)$ & & 0.86 & $(0.61,1.21)$ & \\
\hline MMSE (Reversed) & Per SD increase & 1.15 & $(0.89,1.49)$ & & 1.07 & $(0.80,1.43)$ & \\
\hline GDS & Per SD increase & 1.04 & $(0.78,1.39)$ & & 0.94 & $(0.70,1.27)$ & \\
\hline Frailty Index & Per SD increase & 1.18 & $(0.90,1.54)$ & & 1.08 & $(0.81,1.44)$ & \\
\hline Physical frailty & Per point increase & 1.12 & $(0.91,1.54)$ & & 0.98 & $(0.80,1.21)$ & \\
\hline \multicolumn{8}{|l|}{ Binary score } \\
\hline TUG & $>=9$ vs. $<9 \mathrm{~s}$ & 2.74 & $(1.75,4.30)$ & $* * *$ & 2.02 & $(1.26,3.25)$ & ** \\
\hline GV & $<1.0 \mathrm{~m} / \mathrm{s}$ & 0.78 & $(0.49,1.25)$ & & 1.16 & $(0.72,1.88)$ & \\
\hline KES & $15 \mathrm{~kg}(\mathrm{M}), 11 \mathrm{~kg}(\mathrm{~F})$ & 1.78 & $(1.20,2.65)$ & $* *$ & 1.80 & $(1.20,2.69)$ & ** \\
\hline POMA & $24 / 25$ & 1.15 & $(0.68,1.94)$ & & 1.02 & $(0.59,1.76)$ & \\
\hline MMSE & $\leq 23$ vs. $\geq 24$ & 0.80 & $(0.47,1.35)$ & & 1.02 & $(0.58,1.79)$ & \\
\hline GDS & $\geq 5$ vs. $<5$ & 0.93 & $(0.37,2.34)$ & & 0.84 & $(0.32,2.16)$ & \\
\hline Frailty Index & $\geq 0.15$ vs. $<0.15$ & 1.71 & $(1.08,2.70)$ & $*$ & 1.50 & $(0.25,1.10)$ & \\
\hline Physical frailty & $3-5$ vs. $0-2$ & 0.73 & $(0.37,1.44)$ & & 0.50 & $(0.25,1.01)$ & \\
\hline
\end{tabular}

Abbreviation: HR: hazard ratio; ${ }^{*} p<0.05 ;{ }^{* *} p<0.01 ;{ }^{* * *} p<0.001$. Model 1 : All physical and functional performance measure included in the same model together. Model 2: All physical and functional performance measure included in the same model together with covariates (age, sex, education, housing status, living alone, smoking, physical activity, social activity, productive activity, heart disease, stroke, diabetes/prediabetes, hypertension, chronic kidney disease and multi-morbidity). Binary cut-offs shown are commonly used in previous research and clinical applications. 
Table 4. Predictive accuracy of TUG for mortality compared to gait velocity, frailty index, and physical frailty.

\begin{tabular}{|c|c|c|c|c|c|c|c|c|c|}
\hline Measures & AUC & $95 \% \mathrm{CI}$ & & $p$ & Cut-off & Sensitivity & Specificity & PPV & NPV \\
\hline \multirow[t]{5}{*}{ TUG } & 0.737 & $(0.693,0.781)$ & (a) & **** & $8.0 \mathrm{~s}$ & 0.856 & 0.488 & 0.062 & 0.988 \\
\hline & & & (b) & $* * *$ & $9.0 \mathrm{~s}$ & 0.656 & 0.696 & 0.079 & 0.981 \\
\hline & & & (c) & $* * *$ & $10.0 \mathrm{~s}$ & 0.468 & 0.804 & 0.087 & 0.974 \\
\hline & & & (d) & $* * *$ & $11.0 \mathrm{~s}$ & 0.351 & 0.870 & 0.097 & 0.971 \\
\hline & & & & & $12.0 \mathrm{~s}$ & 0.261 & 0.918 & 0.102 & 0.969 \\
\hline \multirow[t]{7}{*}{ GV (Reversed) } & 0.666 & $(0.617,0.715)$ & (b) & $* * *$ & $0.8 \mathrm{~m} / \mathrm{s}$ & 0.189 & 0.933 & 0.102 & 0.967 \\
\hline & & & & & $0.9 \mathrm{~m} / \mathrm{s}$ & 0.261 & 0.891 & 0.087 & 0.968 \\
\hline & & & & & $1.0 \mathrm{~m} / \mathrm{s}$ & 0.378 & 0.822 & 0.078 & 0.971 \\
\hline & & & & & $1.1 \mathrm{~m} / \mathrm{s}$ & 0.477 & 0.740 & 0.068 & 0.973 \\
\hline & & & & & $1.2 \mathrm{~m} / \mathrm{s}$ & 0.559 & 0.651 & 0.060 & 0.974 \\
\hline & & & & & $1.3 \mathrm{~m} / \mathrm{s}$ & 0.631 & 0.547 & 0.052 & 0.974 \\
\hline & & & & & $1.4 \mathrm{~m} / \mathrm{s}$ & 0.802 & 0.415 & 0.052 & 0.981 \\
\hline \multirow[t]{4}{*}{ MMSE (Reversed) } & 0.630 & $(0.578,0.682)$ & (c) & $* * *$ & $18 / 19$ & 0.045 & 0.983 & 0.096 & 0.963 \\
\hline & & & & & $23 / 24$ & 0.180 & 0.928 & 0.090 & 0.966 \\
\hline & & & & & $26 / 27$ & 0.324 & 0.816 & 0.062 & 0.968 \\
\hline & & & & & $28 / 29$ & 0.649 & 0.549 & 0.054 & 0.975 \\
\hline \multirow[t]{6}{*}{ Frailty Index } & 0.620 & $(0.561,0.678)$ & (a) & $* * *$ & 0.070 & 0.766 & 0.390 & 0.041 & 0.969 \\
\hline & & & & & 0.080 & 0.712 & 0.480 & 0.044 & 0.971 \\
\hline & & & & & 0.090 & 0.658 & 0.482 & 0.048 & 0.973 \\
\hline & & & & & 0.150 & 0.369 & 0.836 & 0.082 & 0.971 \\
\hline & & & & & 0.210 & 0.207 & 0.949 & 0.139 & 0.968 \\
\hline & & & & & 0.250 & 0.117 & 0.974 & 0.151 & 0.965 \\
\hline \multirow[t]{2}{*}{ Physical frailty } & 0.610 & $(0.560,0.669)$ & (d) & $* * *$ & $0 / 1-5$ & 0.667 & 0.520 & 0.052 & 0.975 \\
\hline & & & & & $0-2 / 3-5$ & 0.108 & 0.954 & 0.085 & 0.964 \\
\hline
\end{tabular}

${ }^{* * *} p<0.001$, (a) TUG vs. Frailty index; (b) TUG vs. GV; (c) TUG vs. MMSE; (d) TUG vs. Physical frailty. Binary cut-offs shown cover a range commonly used in previous research and clinical applications. Only predictors with AUC above 0.60 were shown. Abbreviations: AUC: area under the curve; PPV: positive predictive value; NPV: negative predictive value. AUC for age: 0.730 (95\% Cl: 0.681-0.778)

A TUG cut-off of $8.0 \mathrm{~s}$ was associated with high sensitivity to 0.856 (with low specificity of 0.488 ), and TUG of $10.0 \mathrm{~s}$ was associated with high specificity of 0.804 (with low sensitivity of 0.468). A TUG cut-off of $9.0 \mathrm{~s}$ was associated with optimal sensitivity and specificity of 0.656 and 0.696 , respectively.

We conducted further stratified analyses by sex and age groups and found consistent associations and similar predictive accuracy for both men and women and younger $(<75)$ and older $(\geq 75)$ individuals (Supplementary Tables 1 and 2).

\section{DISCUSSION}

In this study, we re-capitulated previous observations that physical and functional measures predict mortality risk. Notably, we showed that TUG, gait speed, KES, FEV ${ }_{1}$, and frailty were significantly associated with increased mortality, even after adjusting for sociodemographic, lifestyle, and traditional disease and health behavioural risk markers. Diabetes, cardiovascular disease, and multimorbidity were also associated with increased mortality risks but low predictive accuracy in this cohort. Notably, compared with standardized units using their SD value, TUG showed the strongest hazard ratio for mortality risk among physical and functional measures. The AUC's for all measures clearly showed that the discriminant accuracy for predicting mortality risk was highest for TUG. The finding remained consistent, whether the TUG was analyzed as a continuous variable or a binary categorical variable with the cut-off of $9 \mathrm{~s}$.

Previous studies have reported similarly that TUG predicts mortality [17-23]. Among them, three studied only men [17] or women [18, 19]; one studied middleaged postmenopausal women [19]; three were Asian studies [21-23], of which one evaluated short-term 2year mortality risk [22], and one evaluated cardiovascular mortality [23]. Only a few studies, 
beside our study, evaluated TUG alongside other physical or functional measures: one study evaluated two measures (TUG and handgrip strength) [22], another study evaluated four measures (TUG, handgrip strength, five times sit-to-stand test, standing balance) [17], and another study also evaluated four measures (TUG, usual gait velocity, functional reach, one-leg stance) [18]. Our finding showing TUG to have surpassing predictive accuracy for long-term mortality is consistent with the findings reported of older men aged 71-86 in Belgium [17], and another cohort of older men and women aged 65-94 in Singapore [22]. However, differing results were reported by Idland et al., who followed up a small group of 300 communitydwelling older women (mean age 80.9 years) for 13.5 years showing that usual gait velocity was the strongest predictor for all-cause mortality [18]. We performed stratified analyses by sex and found consistent associations and predictive accuracy for both men and women.

The TUG is a complex test of functional mobility that reflects strength, balance and mobility through assessing the ability to transfer, sit-to-stand, walk, and turn $[9,10]$. The sit-to-stand component includes a sequence of multiple subtasks, requiring forward movement of the centre-of-mass while still seated (preparatory to standing), acceleration of the centre-ofmass in the anterior-posterior and vertical plane, pushoff, and stabilization once standing is achieved. The walking component requires appropriate initiation of stepping, acceleration and deceleration, and preparation to turn twice. The first turning sequence and the final turning around to sit down requires some level of planning, orientation in space and organization. The transfer and turning components are thus cognitively demanding, particularly on tasks of executive function [24].

The significant correlations between TUG and other physical and functional measures suggest that they have overlapping and non-overlapping domains of physical, cognitive and functional performance with each other. TUG is less correlated with muscle strength (KES) than with gait speed. This is in accord with observations [25] that muscle strength partially determines variations in gait performance, besides other determinants such as reaction time, balance, and proprioception.
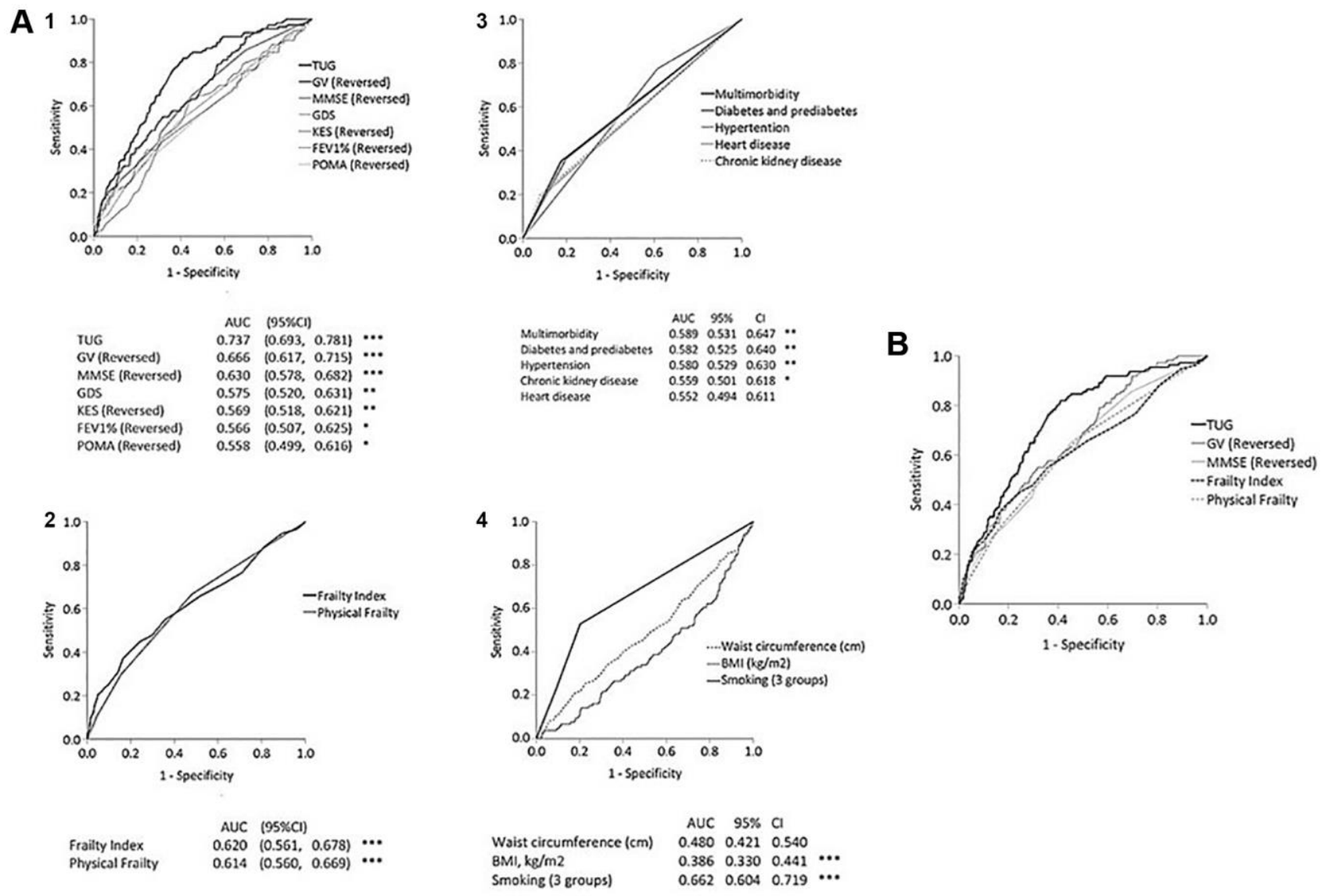

Figure 1. (A) Receiver operating curves of 1-year mortality prediction by physical and functional tests (panel 1), frailty index and physical frailty (panel 2), chronic disease and multi-morbidity (panel 3), and smoking, BMI and waist circumference (panel 4). (B) Receiver operating curves of 10 -year mortality prediction by TUG, GV, MMSE, FI and physical frailty. 
Furthermore, physical performance tests decline faster than muscle decline in the older population [26]. GV was also shown in this study to be more strongly predictive of mortality than muscle strength.

Muscle strength and gait speed are recommended for diagnosing sarcopenia and assessing its severity, respectively [27]. TUG's strong association with mortality is likely due to its ability to identify sarcopenia and frailty; both documented to predict mortality [7, 28]. Sarcopenia, involving the accelerated loss of generalized skeletal muscle mass and function, is considered a precursor and component $[29,30]$ of frailty, which increases the vulnerability to adverse health outcomes. Sarcopenia is about twice as common as frailty, depending on the criteria used [29]; hence not all sarcopenic older people are frail. Two widely accepted operational conceptualizations of frailty are used in this study: the FI considers the cumulative deficits from all diagnosable health conditions; the other physical phenotype of frailty is more closely related to sarcopenia but includes inactivity and exhaustion as additional criteria. Per other studies [7], FI appears to be a stronger predictor of mortality in this study.

Taken together, TUG thus provides more information in a single test than GV, POMA, FEV1 or MMSE alone. It also shows a surpassing accuracy than these physical and functional tests, as well as known disease and health risk markers in predicting mortality. Among the latter, only smoking showed a relatively high AUC of 0.662 , whereas BMI and central obesity showed AUCs significantly below 0.50 , consonant with their wellknown paradoxical 'protective' effect on mortality that has been reported in numerous studies [31]. On the other hand, age showed a higher AUC of 0.730 . Although the TUG appears to have only marginally higher AUC than age in predicting mortality, this does not detract from its potential clinical utility. TUG differs from age in being a modifiable risk predictor that provide clinically useful information for targeted intervention to reduce mortality risk.

\section{TUG cut-off}

Our results align with previous studies showing a monotonic increase of mortality risk per SD increase in TUG [28]. There is no recommended cut-off for mortality prediction. Various optimal cut-off points are recommended specifically for different predicted adverse outcomes and different population groups of healthy and unwell persons. For example, the American Geriatrics Society (AGS) and British Geriatrics Society (BGS) guidelines recommended a TUG cut-off of $13.5 \mathrm{~s}$ for fall risk prediction of community-dwelling older adults [32].
Asian older adults have a lower TUG than the Caucasian population due to the differences in habitual gait speed [33]. Two studies of Japanese and Singaporean older adults suggest appropriate cut-offs of $9.0 \mathrm{~s}$ or $9.5 \mathrm{~s}$ for ADL disability risk among Asians [33, 34]. Consistent with these studies, TUG cut-off of $9.0 \mathrm{~s}$ gave the optimal balance of sensitivity (0.656) and specificity (0.696), whereas a cut-off of $8.0 \mathrm{~s}$ increases the sensitivity to 0.856 (while lowering the specificity to 0.488 ), and a higher cut-off of $10 . \mathrm{s}$ increases the specificity to 0.804 (while lowering the sensitivity to 0.468 ).

\section{Clinical implications}

Our findings contribute to a greater appreciation of the TUG as a powerful clinical tool predicting not only physical and cognitive impairment, sarcopenia, frailty, and other adverse health outcomes [11-15], but longterm mortality as well. The TUG appears unique among other physical and functional measures commonly explored for use as prognostication tools in clinical research and practice. Its overall discriminant accuracy for mortality (AUC $=0.737$ ) is no less than other accepted risk prediction or prognostication tools such as the Framingham risk index for cardiovascular disease mortality (AUC $=0.61)$ [35] or the BODE score for chronic obstructive pulmonary disease $(\mathrm{AUC}=0.71$ ) [36].

Further studies should explore whether combinations of clinical and functional markers could improve its prognostication value. Already, the TUG has been recommended by the AGS and BGS guidelines for fall risk prediction of community-dwelling older adults. As such there is broader justification for routine screening with the TUG (cut-off of $\geq 9 \mathrm{~s}$ ) for early comprehensive assessment and intervention, particularly with clinical consideration of patients' life expectancy during shared clinical decision making regarding chronic disease management, major surgeries and cancer screening.

\section{Strengths and limitations}

Our study is uniquely able to evaluate the TUG alongside many clinical measures of physical and functional health status to compare their relative strengths and limitations for clinical use. We could do this in a large sample community-based cohort with diverse demographic, socio-economic and health characteristics. Follow up over 10 years for mortality was complete using computerized search for deaths via the National Death Registry. The results are reasonably generalizable to other Asian populations, but additional studies in other non-Asian ethnic populations should be conducted. 


\section{MATERIALS AND METHODS}

\section{Participants and setting}

The Singapore Longitudinal Ageing Study is a prospective population-based study of ageing and health transitions of older adults aged 55 and above in Singapore. The current SLAS-2 study cohort was recruited between 2009 and 2013 from the South West and South Central regions of Singapore. A total of 3270 recruited participants underwent assessments for an extensive range of psychosocial, lifestyle and behaviour, medical, biological, physiological, diet and nutrition, physical and neurocognitive functioning, and health status variables. Previous publications have described the details of the participants' recruitment and measurements [37]. The present study involved 2906 participants who provided baseline data who were followed up to 9 years (mean of 5.8) years for mortality. Participants who were not included in the mortality follow-up study did not have complete baseline data for physical, cognitive, and functional tests and did not differ substantially in baseline characteristics from the participants in this study. The study was approved by the National University of Singapore Institutional Review Board, and written informed consent was obtained.

\section{Baseline measurements}

\section{Physical and functional performance}

Timed Up-and-Go (TUG) was measured by the time taken by the participant to stand up from an armchair (46 cm height), walk 3 metres, turn, walk back to the chair, and sit down again. The participants wore their regular footwear and used their customary walking aid, if required. Participants walked at their fastest pace with no physical assistance given. The test was administered twice, and the best performance time was used [8]. Various TUG cut-offs have been proposed or recommended for falls or disability prediction specific for different populations, and there are no suggested TUG cut-offs for mortality prediction. Asians generally have shorter mean TUG (faster gait speed) than Caucasians [33, 34]. We used an optimal TUG cut-off of 9.0s from receiver operating characteristics (ROC) analyses, consistent with a recommended cutoff of $9.0 \mathrm{~s}$ predicting disability in Japanese older adults [38].

Gait velocity $(G V)$ was measured by the time in seconds taken for the participant to walk 6 metres at their fastest pace, averaged for two trials. Participants performed the test with a dynamic start on a smooth, flat 10-metre walkway with red-tape markers placed at the 0-, 2-, 8, and 10-metre points along the walkway, allowing for acceleration the first 2 metres and deceleration over the last 2 metres. The timing made a stopwatch is started when the toes of the leading foot cross the 2-meter mark and stopped when the toes of the leading foot cross the 8 -meter mark. Cut-offs for Asians of $<1.0 \mathrm{~m} / \mathrm{s}$ has been recommended by previous studies [39].

Knee extension strength (KES) was measured for the lower limb maximum isometric strength. It was measured with the participant seated, the hip and knee angles at $90^{\circ}$ using the strap and strain gauge component of the Physiological Profile Assessment [40], using three trials' dominant leg average value (in kilograms). Cut-offs of $15 \mathrm{~kg}$ for males and $11 \mathrm{~kg}$ for females based on the lowest quintile value stratified by sex, were used to define low KES [41].

The Performance Oriented Mobility Assessment (POMA) battery measures both static and dynamic balance, with a separate subtest for balance and gait [42]. POMA is commonly used to predict falls and mortality of older adults [43, 44]. A cut-off score of $<25$ indicates a medium to high fall risk.

The Geriatric Depression Scale 15-items (GDS-15) score (0-15) was used to identify the presence of depressive symptoms (GDS 25) [45], and the MiniMental State Examination (MMSE) was used to assess global cognition and identify cognitive impairment (MMSE <23) [46]. Pulmonary function was assessed with the forced expiratory volume in 1 second (FEV1). $\mathrm{FEV}_{1}$ below $70 \%$ of the value predicted by age, sex, ethnicity, and height using local population equations indicates airflow obstruction.

\section{Frailty}

Two widely accepted models were used to measure the frailty status of the participants:

i. Frailty Index (FI) [47]: a cumulative deficit model based on counts of dysfunction and impairment across multiple body systems. A total of 98 non-laboratory based evaluable health deficits were used to construct the index, expressed as a fractional value (number of observed deficits/number of evaluable deficits) from 0 (extremely robust) to 1 (extremely frail) (Supplementary Table 3). FI was analyzed as a continuous variable and binary variable using a cutoff of 0.15 and more to define frailty, based on calculations of stratum-specific likelihood ratios to determine the most appropriate cutoff to discriminate between frailty and non-frailty in predicting mortality in this cohort [44].

ii. Physical frailty: a physical phenotype model used in the Cardiovascular Health Study [48]. We used 5 operationally modified measures described in our 
previous study [41] for assessing shrinking, weakness, slowness, exhaustion and low activity. One point was assigned for the presence of each of the components, and the total summed score (from 0 to 5) was used to categorize participants as robust (0 points), prefrail (1-2 points) and frail (3-5 points).

\section{Covariates}

We collected baseline information such as age, sex and years of education. Participants' housing type: low-end 1-2 room public housing apartments, 3 rooms or a higher-end with 4 rooms or others was used as an indicator of socio-economic status based on the Singapore population census data [49]. Lifestyle factors included participation in 16 categories of physical, social and productive activities described in a previous publication to derive aggregate score based on the number of activities and frequency of participation (on a 5-point Likert scale), with a higher score representing a higher level of participation [50].

\section{Mortality assessment}

Participants' mortality status from baseline up to $31 \mathrm{Dec}$ 2016 was determined using the participants' unique National Registration Identity Card number for computerized record linkage with the National Death Registry through the National Disease Registry Office of the Ministry of Health.

\section{Statistical analysis}

We used Cox proportional hazard models to evaluate the association of TUG, other physical and functional measures, and chronic disease and behavioural risk markers (multi-morbidity, heart disease, diabetes mellitus, hypertension, chronic kidney disease, smoking, BMI, central obesity, frailty index, physical frailty) with mortality in a crude model and two adjusted models. In Model 1, the mortality HR estimate associated with each predictor variable was adjusted for age and sex (but not for ethnicity, as no deaths were observed among the small numbers of non-Chinese participants). Model 2 further adjusted for covariates in Model 1 as well as for education, housing status, living alone, smoking (but not alcohol, due to small sample size), physical activity, social activity, productive activity, heart disease, stroke, diabetes, hypertension, chronic kidney disease and multi-morbidity. Hazard ratios (HR) and 95\% confidence intervals $(95 \% \mathrm{CI})$ were estimated for each physical, functional and clinical predictor as a continuous variable and binary variable. The mortality HR value is variable for different cut-offs along with the range of values of the same predictor variable and for different measurement units of different predictor variables. Thus, for a valid comparison of the strengths of association with mortality between different predictors, we used a standardized approach to show per standard deviation (SD) increment of mortality HR.

The measures in predicting mortality were evaluated using receiver operating characteristic (ROC) curves, and the areas under the curves (AUCs) were compared using the DeLong's method for significance testing [49]. An AUC between 0.7 and 0.8 is considered acceptable discrimination, between 0.8 and 0.9 is deemed excellent discrimination, and more than 0.9 is outstanding discrimination [51]. The discriminant accuracy of various optimal cut-off values was expressed as sensitivity, specificity, positive predictive value, and negative predictive values. Analysis of the data was performed using IBM SPSS version 25 .

\section{CONCLUSIONS}

Our study highlights the superior accuracy of TUG compared to other physical and functional measures in predicting long-term mortality among communitydwelling older adults. Taken together with evidence of the ability of the TUG to predict falls and other adverse health outcomes, the TUG appears to be uniquely positioned for use in early comprehensive geriatric assessment, and particularly in regard to shared clinical decision making requiring the prognostication of future life expectancy.

\section{AUTHOR CONTRIBUTIONS}

CYC and TPN reviewed the literature, designed the study, drafted and revised the manuscript. TPN analyzed the data. PY, KBY, XYG, DQLC contributed to the study design and data collection. All authors reviewed the results and drafts, and approved the final manuscript.

\section{ACKNOWLEDGMENTS}

We thank the following voluntary welfare organizations for their support: Geylang East Home for the Aged, Presbyterian Community Services, St Luke's Eldercare Services, Thye Hua Kwan Moral Society (Moral Neighbourhood Links), Yuhua Neighbourhood Link, Henderson Senior Citizens' Home, NTUC Eldercare Co-op Ltd, Thong Kheng Seniors Activity Centre (Queenstown Centre) and Redhill Moral Seniors Activity Centre. We thank National Registry of Disease Office (NRDO) for performing the computerized record linkage. 


\section{CONFLICTS OF INTEREST}

The authors declare no conflicts of interest related to this study.

\section{FUNDING}

The study was supported by research grants from the Agency for Science Technology and Research (A*STAR) Biomedical Research Council (BMRC) [Grant: 08/1/21/19/567] and from the National Medical Research Council [Grant: NMRC/1108/2007].

\section{REFERENCES}

1. Nybo H, Petersen HC, Gaist D, Jeune B, Andersen K, McGue M, Vaupel JW, Christensen K. Predictors of mortality in 2,249 nonagenarians--the Danish 1905Cohort Survey. J Am Geriatr Soc. 2003; 51:1365-73. https://doi.org/10.1046/j.1532-5415.2003.51453.x PMID:14511155

2. Marengoni A, von Strauss E, Rizzuto D, Winblad B, Fratiglioni L. The impact of chronic multimorbidity and disability on functional decline and survival in elderly persons. A community-based, longitudinal study. J Intern Med. 2009; 265:288-95. https://doi.org/10.1111/i.1365-2796.2008.02017.x PMID:19192038

3. Feng L, Zin Nyunt MS, Gao Q, Feng L, Yap KB, Ng TP. Cognitive Frailty and Adverse Health Outcomes: Findings From the Singapore Longitudinal Ageing Studies (SLAS). J Am Med Dir Assoc. 2017; 18:252-58. https://doi.org/10.1016/i.jamda.2016.09.015 PMID:27838339

4. Ho CS, Jin A, Nyunt MS, Feng L, Ng TP. Mortality rates in major and subthreshold depression: 10-year follow-up of a Singaporean population cohort of older adults. Postgrad Med. 2016; 128:642-47. https://doi.org/10.1080/00325481.2016.1221319 PMID:27500920

5. Panizza JA, James AL, Ryan G, de Klerk N, Finucane KE. Mortality and airflow obstruction in asthma: a 17year follow-up study. Intern Med J. 2006; 36:773-80. https://doi.org/10.1111/i.1445-5994.2006.01214.x PMID: 17096740

6. White DK, Neogi T, Nevitt MC, Peloquin CE, Zhu $Y$, Boudreau RM, Cauley JA, Ferrucci L, Harris TB, Satterfield SM, Simonsick EM, Strotmeyer ES, Zhang Y. Trajectories of gait speed predict mortality in wellfunctioning older adults:the Health, Aging and Body Composition study. J Gerontol A Biol Sci Med Sci. 2013; 68:456-64. https://doi.org/10.1093/gerona/gls197
PMID:23051974

7. Kojima G, Iliffe S, Walters K. Frailty index as a predictor of mortality: a systematic review and metaanalysis. Age Ageing. 2018; 47:193-200. https://doi.org/10.1093/ageing/afx162 PMID:29040347

8. Podsiadlo D, Richardson S. The timed "Up \& Go": a test of basic functional mobility for frail elderly persons. J Am Geriatr Soc. 1991; 39:142-48. https://doi.org/10.1111/i.1532-5415.1991.tb01616.x PMID:1991946

9. Herman T, Giladi N, Hausdorff JM. Properties of the 'timed up and go' test: more than meets the eye. Gerontology. 2011; 57:203-10. https://doi.org/10.1159/000314963 PMID:20484884

10. Janssen WG, Bussmann HB, Stam HJ. Determinants of the sit-to-stand movement: a review. Phys Ther. 2002; 82:866-79.

PMID: 12201801

11. Chun SH, Cho B, Yang HK, Ahn E, Han MK, Oh B, Shin DW, Son KY. Performance on physical function tests and the risk of fractures and admissions: Findings from a national health screening of 557,648 community-dwelling older adults. Arch Gerontol Geriatr. 2017; 68:174-80.

https://doi.org/10.1016/i.archger.2016.10.008 PMID:27810666

12. Donoghue OA, Savva GM, Cronin H, Kenny RA, Horgan NF. Using timed up and go and usual gait speed to predict incident disability in daily activities among community-dwelling adults aged 65 and older. Arch Phys Med Rehabil. 2014; 95:1954-61. https://doi.org/10.1016/i.apmr.2014.06.008 PMID:24977931

13. Hirano $K$, Imagama $S$, Hasegawa $Y$, Ito Z, Muramoto A, Ishiguro N. Impact of low back pain, knee pain, and timed up-and-go test on quality of life in communityliving people. J Orthop Sci. 2014; 19:164-71. https://doi.org/10.1007/s00776-013-0476-0 PMID:24132792

14. Lee JE, Shin DW, Jeong SM, Son KY, Cho B, Yoon JL, Park BJ, Kwon IS, Lee J, Kim S. Association Between Timed Up and Go Test and Future Dementia Onset. J Gerontol A Biol Sci Med Sci. 2018; 73:1238-43. https://doi.org/10.1093/gerona/g|x261 PMID:29346523

15. Dent $\mathrm{E}$, Lien $\mathrm{C}$, Lim WS, Wong WC, Wong $\mathrm{CH}, \mathrm{Ng} \mathrm{TP}$, Woo J, Dong $B$, de la Vega $S$, Hua Poi PJ, Kamaruzzaman SBB, Won C, Chen LK, et al. The AsiaPacific Clinical Practice Guidelines for the Management of Frailty. J Am Med Dir Assoc. 2017; 
18:564-75.

https://doi.org/10.1016/i.jamda.2017.04.018

PMID:28648901

16. Fried LP, Ferrucci L, Darer J, Williamson JD, Anderson G. Untangling the concepts of disability, frailty, and comorbidity: implications for improved targeting and care. J Gerontol A Biol Sci Med Sci. 2004; 59:255-63. https://doi.org/10.1093/gerona/59.3.m255 PMID:15031310

17. De Buyser SL, Petrovic M, Taes YE, Toye KR, Kaufman $\mathrm{JM}$, Goemaere S. Physical function measurements predict mortality in ambulatory older men. Eur J Clin Invest. 2013; 43:379-86.

https://doi.org/10.1111/eci.12056

PMID:23398295

18. Idland G, Engedal K, Bergland A. Physical performance and 13.5-year mortality in elderly women. Scand J Public Health. 2013; 41:102-108.

https://doi.org/10.1177/1403494812466460

PMID:23178925

19. Tice JA, Kanaya A, Hue T, Rubin S, Buist DS, Lacroix A, Lacey JV Jr, Cauley JA, Litwack S, Brinton LA, Bauer DC. Risk factors for mortality in middle-aged women. Arch Intern Med. 2006; 166:2469-77. https://doi.org/10.1001/archinte.166.22.2469 PMID:17159012

20. Bergland A, Jørgensen L, Emaus N, Strand BH. Mobility as a predictor of all-cause mortality in older men and women: 11.8 year follow-up in the Troms $\varnothing$ study. BMC Health Serv Res. 2017; 17:22.

https://doi.org/10.1186/s12913-016-1950-0 PMID:28068995

21. Otsuka H, Kobayashi $H$, Suzuki K, Hayashi $Y$, Ikeda J, Kushimoto M, Hara M, Abe M, Kato K, Soma M. Mobility performance impacts mortality risk in community-dwelling healthy older adults in Japan: a prospective observational study. Aging Clin Exp Res. 2021; 33:2511-17. https://doi.org/10.1007/s40520-021-01787-1 PMID:33496935

22. Chua KY, Lim WS, Lin X, Yuan JM, Koh WP. Handgrip Strength and Timed Up-and-Go (TUG) Test are Predictors of Short-Term Mortality among Elderly in a Population-Based Cohort in Singapore. J Nutr Health Aging. 2020; 24:371-78. https://doi.org/10.1007/s12603-020-1337-0 PMID:32242204

23. Son KY, Shin DW, Lee JE, Kim SH, Yun JM, Cho B. Association of timed up and go test outcomes with future incidence of cardiovascular disease and mortality in adults aged 66 years: Korean national representative longitudinal study over 5.7 years. BMC
Geriatr. 2020; 20:111.

https://doi.org/10.1186/s12877-020-01509-8 PMID:32192437

24. Donoghue OA, Horgan NF, Savva GM, Cronin H, O'Regan C, Kenny RA. Association between timed up-and-go and memory, executive function, and processing speed. J Am Geriatr Soc. 2012; 60:1681-86.

https://doi.org/10.1111/i.1532-5415.2012.04120.x PMID:22985141

25. Harris-Love MO, Benson K, Leasure E, Adams B, McIntosh V. The Influence of Upper and Lower Extremity Strength on Performance-Based Sarcopenia Assessment Tests. J Funct Morphol Kinesiol. 2018; 3:53.

https://doi.org/10.3390/jfmk3040053 PMID:30533549

26. Chodzko-Zajko WJ, Proctor DN, Fiatarone Singh MA, Minson CT, Nigg CR, Salem GJ, Skinner JS, and American College of Sports Medicine. American College of Sports Medicine position stand. Exercise and physical activity for older adults. Med Sci Sports Exerc. 2009; 41:1510-30. https://doi.org/10.1249/MSS.0b013e3181a0c95c PMID: 19516148

27. Cruz-Jentoft $A J$, Bahat $G$, Bauer J, Boirie $Y$, Bruyère $O$, Cederholm T, Cooper C, Landi F, Rolland Y, Sayer AA, Schneider SM, Sieber CC, Topinkova E, et al, and Writing Group for the European Working Group on Sarcopenia in Older People 2 (EWGSOP2), and the Extended Group for EWGSOP2. Sarcopenia: revised European consensus on definition and diagnosis. Age Ageing. 2019; 48:601.

https://doi.org/10.1093/ageing/afz046

PMID:31081853

28. Liu $P$, Hao $Q$, Hai $S$, Wang $H$, Cao L, Dong B. Sarcopenia as a predictor of all-cause mortality among community-dwelling older people: A systematic review and meta-analysis. Maturitas. 2017; 103:16-22.

https://doi.org/10.1016/j.maturitas.2017.04.007 PMID:28778327

29. von Haehling S, Morley JE, Anker SD. An overview of sarcopenia: facts and numbers on prevalence and clinical impact. J Cachexia Sarcopenia Muscle. 2010; 1:129-33.

https://doi.org/10.1007/s13539-010-0014-2 PMID:21475695

30. Cesari M, Landi F, Vellas B, Bernabei R, Marzetti E. Sarcopenia and physical frailty: two sides of the same coin. Front Aging Neurosci. 2014; 6:192.

https://doi.org/10.3389/fnagi.2014.00192

PMID:25120482 
31. Ahmadi SF, Streja E, Zahmatkesh G, Streja D, Kashyap M, Moradi H, Molnar MZ, Reddy U, Amin AN, Kovesdy $\mathrm{CP}$, Kalantar-Zadeh K. Reverse Epidemiology of Traditional Cardiovascular Risk Factors in the Geriatric Population. J Am Med Dir Assoc. 2015; 16:933-39.

https://doi.org/10.1016/i.jamda.2015.07.014 PMID:26363864

32. Panel on Prevention of Falls in Older Persons, and American Geriatrics Society and British Geriatrics Society. Summary of the Updated American Geriatrics Society/British Geriatrics Society clinical practice guideline for prevention of falls in older persons. J Am Geriatr Soc. 2011; 59:148-57.

https://doi.org/10.1111/j.1532-5415.2010.03234.x PMID:21226685

33. Makizako $H$, Shimada $H$, Doi $T$, Tsutsumimoto $K$, Nakakubo S, Hotta R, Suzuki T. Predictive Cutoff Values of the Five-Times Sit-to-Stand Test and the Timed "Up \& Go" Test for Disability Incidence in Older People Dwelling in the Community. Phys Ther. 2017; 97:417-24.

PMID:28371914

34. Choo PL, Tou NX, Jun Pang BW, Lau LK, Jabbar KA, Seah WT, Chen KK, Ng TP, Wee SL. Timed Up and Go (TUG) Reference Values and Predictive Cutoffs for Fall Risk and Disability in Singaporean CommunityDwelling Adults: Yishun Cross-Sectional Study and Singapore Longitudinal Aging Study. J Am Med Dir Assoc. 2021; 22:1640-45.

https://doi.org/10.1016/j.jamda.2021.03.002 PMID:33819451

35. Chia YC, Gray SY, Ching SM, Lim HM, Chinna K. Validation of the Framingham general cardiovascular risk score in a multiethnic Asian population: a retrospective cohort study. BMJ Open. 2015; 5:e007324.

https://doi.org/10.1136/bmjopen-2014-007324 PMID:25991451

36. de Torres JP, Casanova C, Marín JM, Pinto-Plata V, Divo M, Zulueta JJ, Berto J, Zagaceta J, SanchezSalcedo P, Cabrera C, Carrizo S, Cote C, Celli BR. Prognostic evaluation of COPD patients: GOLD 2011 versus BODE and the COPD comorbidity index COTE. Thorax. 2014; 69:799-804.

https://doi.org/10.1136/thoraxjnl-2014-205770 PMID:24969641

37. Ng TP, Feng L, Nyunt MS, Feng L, Gao $Q$, Lim ML, Collinson SL, Chong MS, Lim WS, Lee TS, Yap P, Yap KB. Metabolic Syndrome and the Risk of Mild Cognitive Impairment and Progression to Dementia: Follow-up of the Singapore Longitudinal Ageing Study Cohort. JAMA Neurol. 2016; 73:456-63. https://doi.org/10.1001/jamaneurol.2015.4899
PMID:26926205

38. Kamide N, Takahashi K, Shiba Y. Reference values for the Timed Up and Go test in healthy Japanese elderly people: determination using the methodology of meta-analysis. Geriatr Gerontol Int. 2011; 11:445-51. https://doi.org/10.1111/i.1447-0594.2011.00704.x PMID:21554510

39. Chen LK, Woo J, Assantachai P, Auyeung TW, Chou MY, lijima K, Jang HC, Kang L, Kim M, Kim S, Kojima T, Kuzuya M, Lee JSW, et al. Asian Working Group for Sarcopenia: 2019 Consensus Update on Sarcopenia Diagnosis and Treatment. J Am Med Dir Assoc. 2020; 21:300-307.e2. https://doi.org/10.1016/j.jamda.2019.12.012 PMID:32033882

40. Lord SR, Menz HB, Tiedemann A. A physiological profile approach to falls risk assessment and prevention. Phys Ther. 2003; 83:237-52. PMID: 12620088

41. Ng TP, Feng L, Nyunt MS, Larbi A, Yap KB. Frailty in older persons: multisystem risk factors and the Frailty Risk Index (FRI). J Am Med Dir Assoc. 2014; 15:63542.

https://doi.org/10.1016/i.jamda.2014.03.008 PMID:24746590

42. Tinetti ME. Performance-oriented assessment of mobility problems in elderly patients. J Am Geriatr Soc. 1986 ; 34:119-26.

https://doi.org/10.1111/j.1532-5415.1986.tb05480.x PMID:3944402

43. Guralnik JM, Simonsick EM, Ferrucci L, Glynn RJ, Berkman LF, Blazer DG, Scherr PA, Wallace RB. A short physical performance battery assessing lower extremity function: association with self-reported disability and prediction of mortality and nursing home admission. J Gerontol. 1994; 49:M85-94. https://doi.org/10.1093/geronj/49.2.m85 PMID:8126356

44. Nam S, Al Snih S, Markides KS. A concordance of selfreported and performance-based assessments of mobility as a mortality predictor for older Mexican Americans. Geriatr Gerontol Int. 2017; 17:433-39.

https://doi.org/10.1111/ggi.12734

PMID:26799255

45. Nyunt MS, Fones C, Niti M, Ng TP. Criterion-based validity and reliability of the Geriatric Depression Screening Scale (GDS-15) in a large validation sample of community-living Asian older adults. Aging Ment Health. 2009; 13:376-82.

https://doi.org/10.1080/13607860902861027 PMID:19484601

46. Feng L, Chong MS, Lim WS, Ng TP. The Modified Mini- 
Mental State Examination test: normative data for Singapore Chinese older adults and its performance in detecting early cognitive impairment. Singapore Med J. 2012; 53:458-62.

PMID:22815014

47. Mitnitski AB, Graham JE, Mogilner AJ, Rockwood K. Frailty, fitness and late-life mortality in relation to chronological and biological age. BMC Geriatr. 2002; 2:1. https://doi.org/10.1186/1471-2318-2-1

PMID:11897015

48. Fried LP, Borhani NO, Enright $P$, Furberg CD, Gardin JM, Kronmal RA, Kuller LH, Manolio TA, Mittelmark MB, Newman A. The Cardiovascular Health Study: design and rationale. Ann Epidemiol. 1991; 1:263-76. https://doi.org/10.1016/1047-2797(91)90005-w PMID:1669507

49. Average monthly household income by household size and type of dwelling. 2019. Available from: https://data.gov.sg/dataset/average-monthlyhousehold-income-by-household-size-and-type-ofdwelling
50. Niti M, Yap KB, Kua EH, Tan CH, Ng TP. Physical, social and productive leisure activities, cognitive decline and interaction with APOE- $\varepsilon 4$ genotype in Chinese older adults. Int Psychogeriatrics. 2008; 20:237-51. https://doi.org/10.1017/S1041610207006655

51. Hosmer DW, Lemeshow S, Sturdivant RX. Applied logistic regression. New York: Wiley. 2000. 


\section{SUPPLEMENTARY MATERIALS}

\section{Supplementary Tables}

Supplementary Table 1. Sex- and age-stratified analyses of hazard ratios of association with mortality for physical and functional performance measures simultaneously present in the same model.

\begin{tabular}{|c|c|c|c|c|c|c|c|c|c|c|c|c|c|}
\hline \multirow{2}{*}{ Measure } & & \multicolumn{2}{|r|}{ Men } & \multicolumn{4}{|c|}{ Women } & \multicolumn{2}{|c|}{ Age $<75$} & \multicolumn{4}{|c|}{ Age $\geq 75$} \\
\hline & & HR & $95 \% \mathrm{CI}$ & $P$ & HR & $95 \% \mathrm{CI}$ & $\boldsymbol{P}$ & HR & $95 \% \mathrm{CI}$ & $\boldsymbol{P}$ & HR & $95 \% \mathrm{CI}$ & $P$ \\
\hline \multicolumn{14}{|c|}{ Standard deviation score } \\
\hline TUG & Per SD increase & 1.77 & $(1.15,2.73)$ & $* *$ & 2.35 & $(1.31,4.22)$ & ** & 1.96 & $(1.26,3.06)$ & $* *$ & 1.85 & $(1.07,3.19)$ & * \\
\hline GV (Reversed) & Per SD increase & 0.76 & $(0.54,1.09)$ & & 1.26 & $(0.76,2.08)$ & & 0.78 & $(0.55,1.13)$ & & 1.34 & $(0.83,2.17)$ & \\
\hline KES & Per SD increase & 1.39 & $(1.02,1.91)$ & $*$ & 1.02 & $(0.67,1.55)$ & & 0.80 & $(0.60,1.06)$ & & 1.18 & $(0.80,1.73)$ & \\
\hline POMA & Per SD increase & 0.76 & $(0.49,1.17)$ & & 0.96 & $(0.60,1.55)$ & & 0.82 & $(0.50,1.36)$ & & 0.89 & $(0.57,1.38)$ & \\
\hline MMSE (Reversed) & Per SD increase & 1.12 & $(0.78,1.60)$ & & 1.51 & $(1.00,2.26)$ & $*$ & 0.87 & $(0.58,1.31)$ & & 1.20 & $(0.84,1.71)$ & \\
\hline GDS & Per SD increase & 0.87 & $(0.60,1.28)$ & & 1.23 & $(0.78,1.92)$ & & 1.03 & $(0.68,1.55)$ & & 1.13 & $(0.74,1.71)$ & \\
\hline Frailty Index & Per SD increase & 1.20 & $(0.85,1.69)$ & & 1.20 & $(0.78,1.86)$ & & 1.27 & $(0.88,1.82)$ & & 0.94 & $(0.64,1.39)$ & \\
\hline Physical frailty & Per point increase & 0.91 & $(0.69,1.19)$ & & 1.34 & $(0.96,1.85)$ & & 1.07 & $(0.78,1.47)$ & & 1.12 & $(0.86,1.46)$ & \\
\hline \multicolumn{14}{|l|}{ Binary score } \\
\hline TUG & $>=9$ vs. $<9 \mathrm{~s}$ & 3.35 & $(1.90,5.90)$ & $* * *$ & 1.59 & $(0.74,3.44)$ & & 2.77 & $(1.55,4.95)$ & $* * *$ & 1.41 & $(0.68,2.92)$ & \\
\hline GV & $<1.0 \mathrm{~m} / \mathrm{s}$ & 0.83 & $(0.45,1.52)$ & & 0.56 & $(0.26,1.22)$ & & 1.04 & $(0.52,2.10)$ & & 0.77 & $(0.40,1.48)$ & \\
\hline KES & $15 \mathrm{~kg}(\mathrm{M}), 11 \mathrm{~kg}(\mathrm{~F})$ & 2.22 & $(1.35,3.66)$ & $* *$ & 1.14 & $(0.58,2.22)$ & & 1.49 & $(0.86,2.56)$ & & 2.12 & $(1.17,3.84)$ & * \\
\hline POMA & $24 / 25$ & 0.95 & $(0.45,2.01)$ & & 1.43 & $(0.66,3.09)$ & & 1.06 & $(0.46,2.41)$ & & 1.20 & $(0.58,2.45)$ & \\
\hline MMSE & $\leq 23$ vs. $\geq 24$ & 1.13 & $(0.46,2.77)$ & & 0.46 & $(0.23,4.51)$ & & 0.97 & $(0.40,2.37)$ & & 0.92 & $(0.47,1.79)$ & \\
\hline GDS & $\geq 5$ vs. $<5$ & 0.73 & $(0.22,2.43)$ & & 0.84 & $(0.19,3.62)$ & & 0.67 & $(0.16,2.83)$ & & 1.15 & $(0.34,3.89)$ & \\
\hline Frailty Index & $\geq 0.15$ vs. $<0.15$ & 1.85 & $(1.03,3.33)$ & * & 2.13 & $(1.01,4.51)$ & $*$ & 2.42 & $(1.30,4.50)$ & $* *$ & 1.00 & $(0.52,1.93)$ & \\
\hline Physical frailty & $3-5$ vs. $0-2$ & 0.41 & $(0.13,1.24)$ & & 1.18 & $(0.47,2.94)$ & & 0.85 & $(0.28,2.63)$ & & 0.62 & $(0.26,1.47)$ & \\
\hline
\end{tabular}

Abbreviation: HR: hazard ratio; ${ }^{*} p<0.05 ;{ }^{* *} p<0.01 ;{ }^{* * *} p<0.001$. All physical and functional performance measure was included in the same model together. Binary cut-offs shown are commonly used in previous research and clinical applications.

Supplementary Table 2. Sex- and age-stratified analyses of area under curve for physical and functional performance measures predicting mortality.

\begin{tabular}{|c|c|c|c|c|c|c|c|c|c|c|c|c|c|c|c|c|}
\hline \multirow{2}{*}{ Measure } & \multicolumn{3}{|c|}{ Men } & \multicolumn{5}{|c|}{ Women } & \multicolumn{3}{|c|}{ Age $<75$} & \multicolumn{5}{|c|}{ Age $\geq 75$} \\
\hline & $\mathbf{A U C}$ & $95 \%$ & CI & $P$ & $\mathbf{A U C}$ & $95 \%$ & CI & $P$ & AUC & $95 \%$ & CI & $P$ & AUC & $95 \%$ & CI & $P$ \\
\hline TUG & 0.737 & 0.684 & 0.790 & **** & 0.741 & 0.662 & 0.820 & $* * *$ & 0.712 & 0.649 & 0.775 & $* * *$ & 0.619 & 0.542 & 0.696 & ** \\
\hline GV (Reversed) & 0.684 & 0.627 & 0.741 & $* * *$ & 0.678 & 0.593 & 0.763 & $* * *$ & 0.645 & 0.580 & 0.710 & $* * *$ & 0.554 & 0.468 & 0.640 & \\
\hline KES & 0.648 & 0.581 & 0.715 & *** & 0.634 & 0.557 & 0.711 & ** & 0.520 & 0.448 & 0.591 & & 0.544 & 0.466 & 0.621 & \\
\hline POMA & 0.550 & 0.495 & 0.605 & & 0.577 & 0.501 & 0.652 & * & 0.531 & 0.476 & 0.586 & & 0.540 & 0.468 & 0.612 & \\
\hline $\begin{array}{l}\text { MMSE } \\
\text { (Reversed) }\end{array}$ & 0.618 & 0.553 & 0.683 & $* * *$ & 0.699 & 0.617 & 0.781 & $* * *$ & 0.575 & 0.508 & 0.643 & $*$ & 0.572 & 0.488 & 0.655 & \\
\hline GDS & 0.550 & 0.488 & 0.613 & & 0.625 & 0.540 & 0.710 & ** & 0.559 & 0.489 & 0.629 & & 0.553 & 0.476 & 0.629 & \\
\hline Frailty Index & 0.611 & 0.536 & 0.685 & ** & 0.664 & 0.566 & 0.762 & ** & 0.576 & 0.491 & 0.661 & & 0.548 & 0.456 & 0.640 & \\
\hline Physical frailty & 0.579 & 0.514 & 0.644 & $*$ & 0.677 & 0.594 & 0.759 & **** & 0.565 & 0.494 & 0.635 & & 0.580 & 0.506 & 0.654 & * \\
\hline Age & 0.696 & 0.634 & 0.759 & $* *$ & 0.750 & 0.669 & 0.832 & $* * *$ & 0.650 & 0.579 & 0.721 & *** & 0.555 & 0.470 & 0.640 & \\
\hline
\end{tabular}

Abbreviation: AUC: area under curve; ${ }^{*} p<0.05 ;{ }^{* *} p<0.01 ;{ }^{* * *} p<0.001$. 


\begin{tabular}{|c|c|}
\hline 1 & History of hypertension \\
\hline 2 & History of high cholesterol \\
\hline 3 & History of diabetes \\
\hline 4 & History of stroke \\
\hline 5 & History of heart attack \\
\hline 6 & History of atrial fibrillation \\
\hline 7 & History of heart failure \\
\hline 8 & History of eye problem \\
\hline 9 & History of hearing loss \\
\hline 10 & History of kidney failure \\
\hline 11 & History of asthma \\
\hline 12 & History of COPD \\
\hline 13 & History of tuberculosis \\
\hline 14 & History of arthritis \\
\hline 15 & History of osteoporosis \\
\hline 16 & History of hip fracture \\
\hline 17 & History of neurodegenerative disorders \\
\hline 18 & History of gastrointestinal problem \\
\hline 19 & History of thyroid problem \\
\hline 20 & History of cancer \\
\hline 21 & History of depression \\
\hline 22 & History of other mental disorders \\
\hline 23 & History of dementia \\
\hline 24 & History of Parkinson's disease \\
\hline 25 & History of other neurological disorder \\
\hline 26 & History of cancer \\
\hline 27 & Illness/condition that changes the kind/amount of food eaten \\
\hline 28 & Difficulty eating due to tooth/mouth problems \\
\hline 29 & Unintended loss $4.5 \mathrm{~kg}$ in last 6 months \\
\hline 30 & Difficulty in falling asleep \\
\hline 31 & Frequent awakenings and difficulty in going back to sleep \\
\hline 32 & Wake up very early and difficulty in going back to sleep \\
\hline 33 & Feel tired in daytimes \\
\hline 34 & Feel excessively sleepy in daytimes \\
\hline 35 & Pain interfere with sleep \\
\hline 36 & Poor sleep quality \\
\hline 37 & Informant report of memory decline/mental ability \\
\hline 38 & Less able to manage to find personal belonging at home \\
\hline 39 & Less able to manage own finance \\
\hline 40 & Less able to manage to keep appointment \\
\hline 41 & Less able to read for over 5 minutes at a time \\
\hline 42 & Cognitive impairment (age-education- adjusted MMSE < 23) \\
\hline 43 & Poorer memory compared to other of similar age \\
\hline 44 & Poorer memory/mental abilities compared to earlier period \\
\hline 45 & Less able to remember things about family and friends (compared to 1 year ago) \\
\hline 46 & Less able to remember things happened recently (compare to 1 year ago) \\
\hline 47 & Less able to remember appointment and social arrangement (compared to 1 year ago \\
\hline 48 & Less able to remember the place where things were put (compared to 1 year ago) \\
\hline 49 & Less able to find way in getting around neighbourhood (compared with 1 year ago) \\
\hline 50 & Less able to learn new things (compared to 1 year ago) \\
\hline 51 & Less able to make decision on every matter (compared to 1 year ago) \\
\hline 52 & Less able to follow news and understand what is going on (compared to 1 year ago) \\
\hline 53 & Less able to handling money (compared to 1 year ago) \\
\hline 54 & Less able to choose or use the right words (compared to 1 year ago) \\
\hline 55 & Less able to concentrate (compared to 1 year ago) \\
\hline
\end{tabular}


Health is fair or poor

Health limited in doing moderate activities during typical day

Health limited in climbing stairs during typical day

Health limited in accomplishing lesser

Health limited in work/other activities

Accomplish less because of emotional problems

Can't do work or other activities well because of emotional problems

Pain interfere with normal work

Not felt calm and peaceful

Have lots of energy

Felt downhearted and low

Physical health/emotional problems interfere with social activities past 4 weeks

Have problem with Mobility

Have problem with Self-care

Have problem with Usual activity

Have Pain or discomfort moderate to extreme

Have moderate to extreme anxiety or depression

Life fairly to very boring

Life fairly to very sad

Life fairly to very hard

Very lonely

Depressive symptoms (GDS > $=5$ )

Hospitalization in past 1 year

Polypharmacy ( $>=5$ medication)

Bowel incontinence

Bladder incontinence

Dependent on personal grooming

Dependent on toilet use

Dependent on feeding

Dependent on transfer (from bed to chair \& back)

Dependent on mobility (about the house)

Dependent on Dressing

Dependent on stairs climbing

Dependent on bathing

FEV1/FVC $<0.70$

Chronic cough

Chronic sputum

Breathlessness

Body mass loss $\left(\mathrm{BMI}<18.5 \mathrm{~kg} / \mathrm{m}^{2}\right)$

Slow gait

Weakness

Exhaustion

Low physical activity 